NOTE

\title{
Key research questions of global importance for cetacean conservation
}

\author{
E. C. M. Parsons ${ }^{1, *}$, S. Baulch ${ }^{2}$, T. Bechshoft' ${ }^{3,4}$, G. Bellazzi ${ }^{5}$, P. Bouchet $^{6}$, \\ A. M. Cosentino ${ }^{5}$, C. A. J. Godard-Codding ${ }^{7}$, F. Gulland ${ }^{8}$, M. Hoffmann-Kuhnt ${ }^{9}$, \\ E. Hoyt ${ }^{10}$, S. Livermore ${ }^{11}$, C. D. MacLeod ${ }^{12}$, E. Matrai ${ }^{10,13}$, L. Munger ${ }^{14}$, M. Ochiai ${ }^{15}$, \\ A. Peyman $^{16}$, A. Recalde-Salas ${ }^{17}$, R. Regnery $^{16}$, L. Rojas-Bracho ${ }^{18}$, \\ C. P. Salgado-Kent ${ }^{17}$, E. Slooten ${ }^{19}$, J. Y. Wang ${ }^{20}$, S. C. Wilson ${ }^{21}$, A. J. Wright ${ }^{1}$, \\ S. Young ${ }^{22}$, E. Zwamborn ${ }^{23}$, W. J. Sutherland ${ }^{24}$ \\ All affiliations are given in the Appendix
}

\begin{abstract}
Limited resources and increasing environmental concerns have prompted calls to identify the critical questions that most need to be answered to advance conservation, thereby providing an agenda for scientific research priorities. Cetaceans are often keystone indicator species but also high profile, charismatic flagship taxa that capture public and media attention as well as political interest. A dedicated workshop was held at the conference of the Society for Marine Mammalogy (December 2013, New Zealand) to identify where lack of data was hindering cetacean conservation and which questions need to be addressed most urgently. This paper summarizes 15 themes and component questions prioritized during the workshop. We hope this list will encourage cetacean conservation-orientated research and help agencies and policy makers to prioritize funding and future activities. This will ultimately remove some of the current obstacles to science-based cetacean conservation.
\end{abstract}

KEY WORDS: Marine mammal $\cdot$ Research $\cdot$ Marine conservation $\cdot$ Flagship species $\cdot$ Keystone species

\section{INTRODUCTION}

Over the past decade, limited resources and increasing environmental concerns have prompted calls to prioritize scientific research and identify critical questions that most need to be answered to advance conservation (Sutherland et al. 2011). This exercise has been completed for a number of scientific disciplines (Pretty et al. 2010), in various geographical regions (Sutherland et al. 2006, Morton et al. 2009, Fleishman et al. 2011, Walzer et al. 2013, Kennicutt et al. 2014) as well as on a global level (Sutherland et al. 2009, 2011, 2012). One of the first global exercises to prioritize research questions that urgently need to be answered, the paper by Suther-

\footnotetext{
*Corresponding author: ecm-parsons@earthlink.net
}

land et al. (2009) has since become one of Conservation Biology's most frequently downloaded and cited papers, showing a need for such priority-setting papers. Such efforts have not only proved useful to researchers, but also to government agencies and industry partners for optimizing funding allocation for research (Sutherland et al. 2009, Rudd 2011). Related work by Rudd \& Fleishman (2014) showed that questions that were considered to be priorities by scientists were ranked similarly by policy makers and practitioners, emphasizing the utility of these exercises for conservation decision-makers.

The typically terrestrial focus of these exercises led Cooke et al. (2010) to discuss whether a similar approach focusing on fisheries and aquatic environ-

() The authors 2015. Open Access under Creative Commons by Attribution Licence. Use, distribution and reproduction are unrestricted. Authors and original publication must be credited. 
ments would be valuable. Accordingly, between 2011 and 2012, a list of 71 research questions that constituted obstacles to effective marine conservation was developed (Parsons et al. 2014). This list is already being used to prioritize discussions on marine conservation, being used, for example, as a benchmark to select abstracts submitted to the Society for Conservation Biology's 2014 International Marine Conservation Congress. Similar marineoriented exercises have also recently been conducted with a focus on coastal issues (Rudd \& Lawton 2013), Canadian ocean environments (Fissel et al. 2012), and 2 marine taxa: marine turtles (Hamann et al. 2010) and seabirds (Lewison et al. 2012). A few questions in the above-mentioned exercises are broadly relevant to cetacean conservation, but none specifically addressed this taxon.

Cetaceans capture public and media attention as well as political interest and are often referred to as 'charismatic species' (Hoyt 2011). Moreover, cetaceans are often an essential part of marine ecosystems (Katona \& Whitehead 1988), helping to maintain ecosystem health and integrity (Bowen 1997, Sergio et al. 2008). Additionally, some cetaceans are reported as sentinel or indicator species for the state of marine ecosystems (IOC 2001, Moore 2008, Godard-Codding et al. 2011). Cetaceans are often wide ranging and are found in diverse habitats from rivers and shallow coastal waters to abyssal canyons. They encounter a multitude of anthropogenic threats, including incidental by-catch in fishing gear, exposure to pathogens and pollutants, collisions with shipping vessels, and underwater noise (Parsons et al. 2012). Cetaceans can also be economically important. The whale-watching industry is worth over a billion dollars a year (Hoyt 2001, O'Connor et al. 2009) and is the main contributor to the income and employment of several coastal communities (Parsons et al. 2003). Hence, a special list of priority questions for cetacean conservation is arguably warranted. Geographic, cultural, and economic context influences conservation needs and actions; thus, our objective was to identify those questions that, if answered, would most benefit cetacean conservation around the world.

\section{METHODS}

A dedicated workshop was held at the 20th Biennial Conference of the Society for Marine Mammalogy (7 December 2013, at the University of Otago, in Dunedin, New Zealand). The full-day workshop was advertised to all members of the Society for Mar- ine Mammalogy through the conference website and email distribution lists and was freely open to any conference participant who wished to attend. There was a workshop registration fee, but this was heavily subsidized by the Society for Conservation Biology Marine Section $(80-100 \%$ depending on financial need), meaning that nobody was financially precluded from attending. Participants represented academia, governmental agencies, and non-governmental organizations from 12 countries in North America, South America, Europe, Asia, and Australasia. Participants, as well as individuals interested in the workshop but unable to attend, were asked to submit questions beforehand via email (co-authors of the present paper include members of both categories). In addition, prominent individuals in cetacean conservation were also approached to supply questions and participate; these included representatives from non-governmental agencies engaged in conservation policy, implementation, and interventions (e.g. Whale and Dolphin Conservation; the Marine Section of the Society for Conservation Biology; the Joint Marine Mammal Protected Area Task Force of the International Union for Conservation of Nature [IUCN]; and others), the US Marine Mammal Commission, and the Chair of the Cetacean Specialist group from the IUCN. A total of 33 people participated in contributing and commenting on the questions.

It was requested that submissions be limited to questions that:

(a) held back cetacean conservation in the absence of answers;

(b) would greatly refine and improve cetacean conservation if answered;

(c) were not answerable simply by a 'yes,' 'no,' or 'depends' response;

(d) could be answered if appropriate funds for research were available; and

(e) could be answered using natural science or social science methods.

During the workshop, the list of submitted questions $(n=88)$ was reviewed by attendees, and specific questions were added as deemed relevant. During this review process, however, it became apparent that some questions addressed different aspects of the same issue or theme. The workshop participants then grouped the questions into themes to develop the list presented here. The original questions were reviewed once more to either allocate the questions to one of the subset themes, or to add an additional theme or question if a gap was identified. The resulting groups of questions under the identified 15 themes were again reviewed and edited to make the 
questions as inclusive, but as specific and answerable, as possible.

\section{RESULTS}

The 15 identified themes of global importance for cetacean conservation, and their component questions, are listed below. Please note that these are not ranked in order of importance. Similarly, themes or questions may vary in importance or relevance to different species or populations.

1. Prioritizing conservation projects for optimal use of funds and efforts. Access to funding is usually restricted. How can limited funds be optimally allocated to maximize tangible long-term conservation results? How can we better select specific cetacean populations as conservation priorities? Which monitoring methods are most appropriate and cost effective? Which conservation methods (e.g. science advocacy, outreach, regulation, marine protected areas, and marketing) are most effective for these target populations and when should they be applied?

2. Bridging management, policy-making, and conservation science. Managers need science to make informed decisions, but cetacean science (especially long-term research) is expensive to conduct and chronically under-funded. Moreover, cetacean research is often more regulated in comparison to other branches of science, as marine mammals are listed as protected - if not endangered - species in numerous countries around the world, introducing additional bureaucratic oversight/regulation and permitting requirements. How can managers and policy makers be persuaded to better support cetacean conservation science (e.g. streamlined and simplified permit processes, enhanced funding, and improved international cooperation and consistency)?

3. Achieving compliance in the management process. Multiple legislative instruments have been implemented around the world with the aim of better protecting cetacean populations, but in many cases have achieved limited (or unquantified) success. What are the current barriers to monitoring and achieving compliance? What are the best methods to achieve compliance at every step of the management process with treaties, laws, and/or regulations? For example, the toolbox for increasing levels of compliance includes enforcement, incentives such as accreditation and subsidies, education, within-industry peer pressure, and technological approaches and perhaps improved mechanisms to increase compliance across jurisdictions.
4. Bridging science, policy making, and public engagement. Scientific findings are often overlooked, even ignored, misunderstood, or grossly simplified by the non-scientific community (Michael 1996). How can cetacean scientists better engage with policy makers and the public so that science can lead to improved conservation outcomes for cetaceans?

5. Integrating multidisciplinary research, multiple methods, and non-conventional data. Cetaceans are studied by researchers in different scientific disciplines, using various methods and from different, conventional and non-conventional, platforms. The human dimension of cetacean conservation is important, yet understudied. What are the barriers to building collaboration between multidisciplinary groups? How can data obtained from multidisciplinary research, including social and economic data, traditional ecological knowledge, expert opinion, and citizen science, be better captured, combined, and integrated, for cetacean conservation science?

6. Better understanding of conservation interventions. Interventions, even when based on the latest scientific evidence, are not always effective and can sometimes have negative consequences; one dramatic example is the failed attempt to save the Yangtze river dolphin Lipotes vexillifer from extinction (Dudgeon 2005, Yang et al. 2006, Turvey 2008). How can the short- and long-term success of conservation interventions be better assessed? How do we monitor the unintended consequences of our interventions, including consequences to other populations, species and to the ecosystem?

7. Adapting conservation efforts to a changing environment. Future environmental changes are multiple and inevitable. How will current and predicted environmental changes, including climate change, human population growth, decrease in freshwater supplies, increase in coastal development, and anthropogenic pollution (including noise), affect cetacean ranges, population structure, habitat use, and health, and how do we conserve cetaceans bearing in mind these changes?

8. Monitoring key activities and populations for conservation. Cetacean populations are subject to a large number of anthropogenic pressures. How can cetaceans, human activities (e.g. development projects, industry, fisheries, and tourism) and their interactions be better monitored and these interactions mitigated? How can the potential extent of cumulative and synergistic impacts be assessed and mitigated? How can the impact of illegal, unregulated, or unmonitored activities be assessed and mitigated? 
9. Fostering cetacean-sustainable activities. Sustainable activities involve altering the status quo by changing traditional business methods and practices, and there are often prejudices against them. What can be done to further engage industry and to support communities (including indigenous societies) to develop and undertake cetacean-sustainable activities?

10. Assessing the value of cetaceans. Cetaceans, like other living resources, have an economic and societal value to communities and countries. Can an overall value of cetaceans be determined (at individual and population levels) including ecological, economic, and societal elements? How can acceptance of these values be encouraged by the public and policy makers and the values appropriately incorporated into policy making?

11. Defining a cetacean conservation unit. There is no overall consensus on an appropriate conservation unit for cetaceans. Identification of conservation units can help with threat identification and management prioritization. How can a 'cetacean conservation unit' (e.g. Wallace et al. 2010) be defined based on current acoustic, taxonomic, genetic, geographic, behavioral, social, ecological, or other features?

12. Including uncertainty in risk assessment. Data typically required for risk assessments are often lacking or limited for those addressing marine mammal populations, which results in uncertainty. How can this uncertainty, and the large natural variability of cetacean physical and physiological responses to human activities (including mitigation), be appropriately incorporated into risk assessments, given the underutilization of precautionary approaches? How can the risk from cumulative impacts (on both a spatial and temporal scale) be better assessed, incorporated, and mitigated for?

13. Managing data deficiency. Many cetacean species are Data Deficient (>35\% ; www.iucnredlist.org). What technologies and methods are needed to best address data gaps hindering conservation especially for data deficient species? How can data deficient cetacean species/populations be successfully conserved/protected, given that policy makers often equate data deficiency as 'no concern' in terms of conservation priorities, or use it as a reason to delay action?

14. Quantifying pain and suffering, their role in health, and their relevance to conservation. Health plays an important role in conservation (Baker 2013) and the viability of cetacean populations (e.g. as mediated through stress responses; Wright et al. 2011). How can the pain and suffering experienced by different species of cetaceans as a result of human activities be better quantified, and what are the possible links between pain, suffering, and health (e.g. chronic stress) in cetaceans? What is the importance of the above with regard to public empathy and its role in conservation?

15. Furthering our understanding of sublethal and nonlethal stressors and their impact on resilience and viability. Cetacean populations are impacted by multiple threats and drivers, but the impacts, both in terms of individual health and at a population level, are often poorly understood. At what point do sublethal and nonlethal impacts compromise the viability of a cetacean population? How do we quantify and model impacts and interactions of multiple, cumulative, and synergistic factors? To what degree are cetaceans able to habituate, cope, tolerate, or adapt? Does removing certain stressors increase resilience to those stressors that remain?

\section{CONCLUSION}

The above list is not exhaustive, given the large number of threats faced by cetaceans worldwide (Halpern et al. 2008, Moore 2014). However, we believe that many issues hindering or obstructing optimal cetacean conservation efforts, as well as conservation of other marine mammal species, are well covered by these questions. We thus hope that this will encourage future efforts in conservation-orientated research of these species and help agencies and policy makers to prioritize funding and future activities to address the above questions and remove some of the current obstacles to science-based cetacean conservation.

Acknowledgements. The workshop was kindly sponsored by the Society for Conservation Biology Marine Section's International Marine Conservation Think Tank Program. We gratefully thank all those who participated in the workshop and who supplied questions for this exercise.

\section{LITERATURE CITED}

Baker L (2013) Why individuals matter. Lessons in animal welfare and conservation. In: Bekoff $M$ (ed) Ignoring nature no more. The case for compassionate conservation. University of Chicago Press, Chicago, IL, p 159-166

Bowen WD (1997) Role of marine mammals in aquatic ecosystems. Mar Ecol Prog Ser 158:267-274

Cooke SJ, Danylchuk AJ, Kaiser MJ, Rudd MA (2010) Is there a need for a '100 questions exercise' to enhance fisheries and aquatic conservation, policy, management and research? Lessons from a global 100 questions exer- 
cise on conservation of biodiversity. J Fish Biol 76: 2261-2286

Dudgeon D (2005) Last chance to see ...: ex situ conservation and the fate of the baiji. Aquat Conserv 15:105-108

Fissel D, Babin M, Bachmayer R, Denman K and others (2012) 40 Priority research questions for ocean science in Canada. Council of Canadian Academies, Ottawa, ON

- Fleishman E, Blockstein DE, Hall JA, Macia MB and others (2011) Top 40 priorities for science to inform US conservation and management policy. BioScience 61:290-300

Godard-Codding CAJ, Clark R, Fossi MC, Marsili L and others (2011) Pacific Ocean-wide profile of CYP1A1 expression, stable carbon and nitrogen isotope ratios, and organic contaminant burden in sperm whale skin biopsies. Environ Health Perspect 119:337-343

Halpern BS, Walbridge S, Selkoe KA, Kappel CV and others (2008) A global map of human impact on marine ecosystems. Science 319:948-952

Hamann M, Godfrey MH, Seminoff JA, Arthur K and others (2010) Global research priorities for sea turtles: informing management and conservation in the 21 st century. Endang Species Res 11:245-269

Hoyt E (2001) Whale watching 2001: worldwide tourism numbers, expenditures and expanding socioeconomic benefits. International Fund for Animal Welfare, Yarmouth Port, MA

Hoyt E (2011) Marine protected areas for whales, dolphins and porpoises. Earthscan, Taylor \& Francis, New York, NY

IOC (Intergovernmental Oceanographic Commission) (2001) The strategic plan for the Health of the Ocean Panel for GOOS. IOC, United Nations Educational, Scientific, and Cultural Organization, Paris

Katona S, Whitehead H (1988) Are Cetacea ecologically important? Oceanogr Mar Biol Annu Rev 26:553-568

> Kennicutt MC II, Chown SL, Cassano JJ, Liggett D and others (2014) Six priorities for Antarctic science. Nature 512:23-25

Lewison R, Oro D, Godley BJ, Underhill L and others (2012) Research priorities for seabirds: improving conservation and management in the 21st century. Endang Species Res 17:93-121

Michael M (1996) Ignoring science: discourses of ignorance in the public understanding of science. In: Irwin A, Wynne B (eds) Misunderstanding science? The public reconstruction of science and technology. Cambridge University Press, Cambridge, p 107-125

> Moore SE (2008) Marine mammals as ecosystem sentinels. J Mammal 89:534-540

Moore MJ (2014) How we all kill whales. ICES J Mar Sci, doi:10.1093/icesjms/fsu008

Morton SR, Hoegh-Guldberg O, Lindenmayer DB, Harriss Olson $\mathrm{M}$ and others (2009) The big ecological questions inhibiting effective environmental management in Australia. Austral Ecol 34:1-9

O'Connor SO, Campbell R, Cortez H, Knowles T (2009) Whale watching worldwide: tourism numbers, expenditures and expanding economic benefits. International Fund for Animal Welfare and Economists at Large, Yarmouth, MA
Parsons ECM, Warburton CA, Woods-Ballard A, Hughes A, Johnston P (2003) The value of conserving whales: the impacts of cetacean-related tourism on the economy of rural West Scotland. Aquat Conserv 13:397-415

Parsons ECM, Bauer A, McCafferty D, Simmonds MP, Wright AJ (2012) An introduction to marine mammal biology and conservation. Jones \& Bartlett Publishing, Sudbury, MA

> Parsons ECM, Favaro B, Aguirre AA, Bauer AL and others (2014) Seventy-one important questions for the conservation of marine biodiversity. Conserv Biol 28: 1206-1214

> Pretty J, Sutherland WJ, Ashby J, Auburn J and others (2010) The top 100 questions of importance to the future of global agriculture. Int J Agric Sustain 8:219-236

Rudd MA (2011) How research-prioritization exercises affect conservation policy. Conserv Biol 25:860-866

Rudd MA, Fleishman E (2014) Policymakers' and scientists' ranks of the top 40 priorities for science to inform resource-management policy in the United States. BioScience 64:219-228

> Rudd MA, Lawton RN (2013) Scientists' prioritization of global coastal research questions. Mar Policy 39:101-111

Sergio F, Caro T, Brown D, Clucas B and others (2008) Top predators as conservation tools: ecological rationale, assumptions, and efficacy. Annu Rev Ecol Evol Syst 39: $1-19$

> Sutherland WJ, Armstrong-Brown S, Armsworth PR, Brereton $\mathrm{T}$ and others (2006) The identification of 100 ecological questions of high policy relevance in the UK. J Appl Ecol 43:617-627

> Sutherland WJ, Adams WM, Aronson RB, Aveling R and others (2009) One hundred questions of importance to the conservation of global biological diversity. Conserv Biol 23:557-567

Sutherland WJ, Fleishman E, Mascia MB, Pretty JP, Rudd MA (2011) Methods for collaboratively identifying research priorities and emerging issues in science and policy. Methods Ecol Evol 2:238-247

Sutherland WJ, Bellingan L, Bellingham JR, Blackstock JJ and others (2012) A collaboratively-derived sciencepolicy research agenda. PLoS ONE 7:e31824

Turvey S (2008) Witness to extinction: how we failed to save the Yangtze River dolphin. Oxford University Press, Oxford

> Wallace BP, DiMatteo AD, Hurley BJ, Finkbeiner EM and others (2010) Regional management units for marine turtles: a novel framework for prioritizing conservation and research across multiple scales. PLoS ONE 5:e15465

Walzer C, Kowalczyk C, Alexander JM, Baur B and others (2013) The 50 most important questions relating to the maintenance and restoration of an ecological continuum in the European Alps. PLoS ONE 8:e53139

Wright AJ, Deak T, Parsons ECM (2011) Size matters: management of stress responses and chronic stress in beaked whales and other marine mammals may require larger exclusion zones. Mar Pollut Bull 63:5-9

> Yang G, Bruford MW, Wei F, Zhou K (2006) Conservation options for the baiji: time for realism? Conserv Biol 20: $620-622$ 
Appendix. Complete list of author affiliations

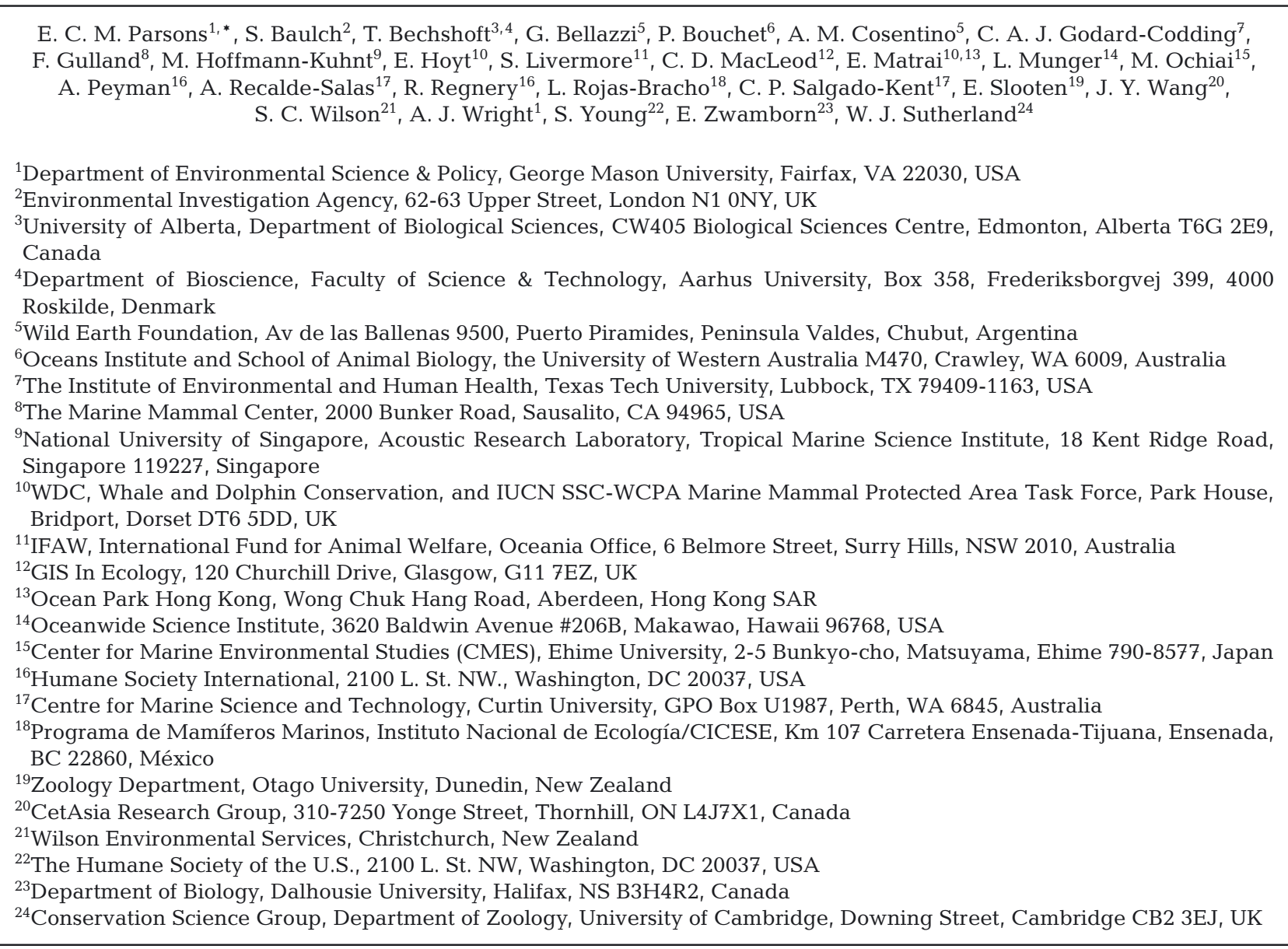

Editorial responsibility: Mark Hamann, Townsville, Queensland, Australia
Submitted: June 13, 2014; Accepted: November 17, 2014 Proofs received from author(s): January 29, 2015 